\title{
Clinical Prevalence of Diseases and Disorders in Buffaloes at the Veterinary Teaching Hospital, Agriculture and Forestry University (AFU), Nepal
}

\author{
B. Regmi ${ }^{1, *}$, I. Dhakal ${ }^{2}$, D. Chetri ${ }^{3}$, M. K. Shah ${ }^{4}$ \\ ${ }^{1}$ Veterinary Laboratory, Pokhara, Nepal. \\ ${ }^{2}$ Army Equine Breeding Center, Chitwan, Nepal. \\ ${ }^{3}$ Director, Veterinary Teaching Hospital, AFU, Nepal. \\ ${ }^{4}$ Department of Surgery \& Pharmacology AFU, Nepal.
}

How to cite this paper: $B$. Regmi, I. Dhakal, D. Chetri, M. K. Shah. (2020) Clinical Prevalence of Diseases and Disorders in Buffaloes at the Veterinary Teaching Hospital, Agriculture and Forestry University (AFU), Nepal. International Journal of the Science of Food and Agriculture, 4(2), 203-210. DOI: $10.26855 /$ ijfsa.2020.06.012

Received: April 20, 2020

Accepted: May 25, 2020

Published: June 11, 2020

*Corresponding author: B. Regmi, Veterinary Laboratory, Pokhara, Nepal. Email: regmibharat2008@gmail.com

\begin{abstract}
A retrospective study was undertaken to determine the occurrence and distribution of diseases in buffaloes based on breed, sex, system affected, diseases type and seasonal variation from the record book of the Veterinary Teaching Hospital, Agriculture and Forestry University from July 2012 to July 2017. A total of 712 buffaloes cases were presented in five years duration, of which $99 \%$ were Murrah crosses followed by local breeds. The cases were categorized on the basis of age group namely yearlings, heifer, adult and senile with the diseases distribution of $5 \%, 23 \%, 62 \%$ and $10 \%$ respectively. Out of the total cases, $86 \%$ were medical followed by $12 \%$ gynecological and $2 \%$ surgical. Parasitic infestation (61.92\%) and mastitis $(10.32 \%)$ were the major medical problems, while the anestrous was the predominant gynecological problems. Surgical cases were remarkably negligible and most were wound related problems. In the fecal examination, $83 \%$ were positive for parasitic infestation such as Nematodiasis (44\%), Paramphistomisiasis (35\%), Protozoan (10\%), Moneiziasis (6\%) and Fascioliasis (5\%). In the hospital, the milk samples positive on California Mastitis Test (CMT) were recommended for bacterial culture and antibiotic sensitivity test. The cultural report revealed that $85 \%$ mastitis was caused by coliform bacteria and $12 \%$ mastitis was due to staphylococcal bacteria. The mastitis cases were predominantly higher in the first and third parity. The highly sensitive antibiotics based on antibiotic sensitivity test were gentamicin (33\%), ciprofloxacin (31\%) and tetracycline (16\%) respectively. Outcome of this study could be insightful for outlining the appropriate disease control and management strategies around the university vicinity.
\end{abstract}

Keywords

Clinical prevalence, Buffalo, Veterinary teaching hospital

\section{Introduction}

Livestock is an integral and indispensable component of farming systems in Nepal which contributes about $12.8 \%$ to the total national gross domestic product (GDP) and 31.5\% to the agricultural GDP [1]. The domestic water buffalo (Bubalus bubalis) contributes a significant share of national milk production and is the major milk producing 
animal. Buffaloes are kept mostly by small-scale producers, who raise one or two animals in mixed crop-livestock systems [2]. Buffaloes are raised also for supply of animal protein, draft power, and manure. At present, the national buffalo population is 5.2 million which contributed for $65.28 \%$ of milk and 54.34\% meat production in the year 2015/16 [3]. The total annual milk production of Nepal is 1.8 million tons (65\% from buffalo and $35 \%$ from cattle). In particular, buffalo enterprise contributes $52.9 \%$ of the livestock share in the national GDP [4]. The major components of livestock GDP are milk and milk products from buffalo and cattle (32.7\% and $24.7 \%$ respectively).

Chitwan has tropical climatic conditions with four main seasons; winter (cold and semi dry to dry), spring (hot and dry), summer or monsoon (very hot and humid) and autumn (moderate climate) in the month December to February, March to May, June to August and September to November respectively [5]. Veterinary Teaching Hospital (VTH) of Agriculture and Forestry University (AFU) is located at the western part of Chitwan where a large number of livestock, pets and poultry species are brought for the diagnosis and treatment of various diseases. Buffalo is one of the major livestock species of Chitwan district with the population of 68,809 (18,166 milking buffaloes), which are contributing to $66.91 \%$ of total milk and $31.26 \%$ of total meat production of the district [3]. The cases are brought mainly from the university periphery and sometimes from the neighboring districts. All the cases brought to the hospital are recorded daily in the register book.

Veterinary hospital is an ideal and reliable source of information about animal diseases with their treatment. Analysis of the case record gives a comprehensive idea about the disease problems at local areas. Recently, Gautam et al. [6] have reported the case flow pattern of different cases registered at the VTH during two years period. But the species wise case flow patterns of various disease and disorders have not been reported yet. Therefore, the present study was aimed to determine the occurrence of diseases and disorders in buffaloes attended at the VTH, AFU including the distribution of diseases based on breed, age, sex, group and seasonal variation from the fiscal year 2012/13 to 2016/17.

\section{Methodology}

The retrospective epidemiological study of diseases was performed using 5 years data from July 2012 to July 2017 recorded at VTH, AFU, Rampur, Chitwan, Nepal. The patient's data we collected from the register book after official permission from the administration of the VTH. All the cases brought to the hospital were diagnosed by the clinicians or faculty veterinarians mainly on the basis of general, physical and clinical examinations with the limited laboratory confirmation. Gastrointestinal parasitic infestations were diagnosed based on fecal examination by light microscopy. Mastitis was diagnosed by California Mastitis Test (CMT) and the positive milk samples were cultured for in-vitro antibiotic sensitivity test. Sometime, the reproductive problems were diagnosed by transrectal ultrasonography. In the in-vitro antibiotic sensitivity test, the different strains of isolated organisms from clinical cases of mastitis were streaked onto Mueller Hinton Agar plates and different antibiotic discs (ciprofloxacin, gentamicin, tetracycline, chloramphenicol, enrofloxacin, amikacin, etc.) were diffused on them. After the discs had been applied, the plates were kept at $10^{\circ} \mathrm{C}$ for 3-4 hours to allow pre-diffusion of the antibiotics. The plates were then incubated at $37^{\circ} \mathrm{C}$ for 24 hours and observed for sensitivity by measuring the zone of inhibition. The results found were recorded as sensitive, intermediate and resistant [7].

All recorded clinical cases were primarily categorized into three major groups on the basis of treatment required. These groups were: (1) Medical cases; (2) Gynaeco-obstetrical cases; and (3) Surgical cases. Mastitis, fecal examination (FE), anorexia/inappetance, poisoning, lameness, enteritis, stress, constipation, skin infections were included in medical cases. FE cases were further classified into paramphistomiasis, nematodiasis, protozoan, moneiziasis, fascioliasis and negative cases. Similarly, mastitis cases included a number of milk samples subjected to the VTH; most of the cases in this category included only the milk samples brought by the owner, not the sick animals. Gynecological cases included pregnancy diagnoses (PD), vaginal prolapse, silent heat, anestrous, and repeat breeding. Surgical cases included tail gangrene, eye injury, tumor, udder wound, castration, dehorning, horn injury, teat obstruction and urolithiasis. Similarly, the cases were broadly classified into fecal examination, mastitis, PD, anestrous and repeat breeding, anorexia, tail gangrene and others under the diseases and disorders. In the age wise occurrence of cases, animals having the age $<1$ year, 1-3 years, 4-8 years and $>8$ years were classified as yearling calf, heifer, adult and senile respectively. Finally, the data were entered into Microsoft excel 2007 and diseases and other health related problems in those five years was analyzed using proportion and simple percentage methods and presented graphically to determine age, sex, breed, group and season wise distribution of diseases.

\section{Results}

In total of 712 cases, 699 (98\%) were she-buffaloes and rest were he-buffaloes, out of which 99\% were Murrah-cross followed by local breed. Age group variations classified into yearling calf, heifer, adult and senile were found to be 34 (5\%), 166 (23\%), $441(62 \%)$ and $71(10 \%)$ respectively (Figure 1A). Figures 1B \& E show the year wise case flow pattern; among the five years, there was an increasing trend of cases flow from the fiscal year 2012/13 to 2015/16 and 
the lowest cases flow was recorded during the year 2016/17. Season wise cases flow presented in the Figure 1C shows that the diseases and disorders recorded were highest during summer season followed by spring, autumn and winter. In the group wise distribution, highest cases were found in the medical group (86\%) and then gynecological group (12\%) followed by least cases in the surgical group (Figure 1F).

A

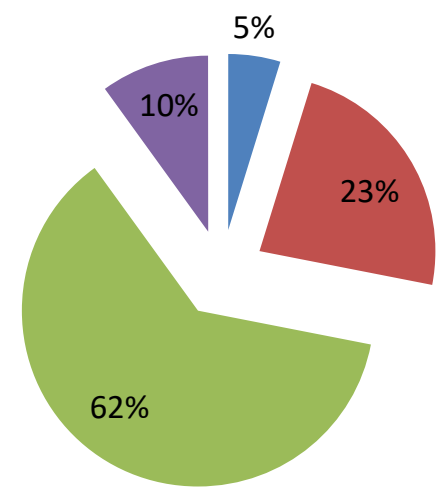

Yearling Calf

Heifer

Adult

- Senior

C

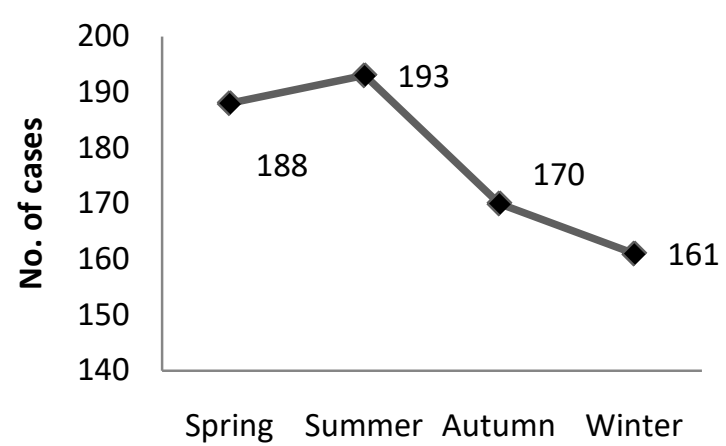

B

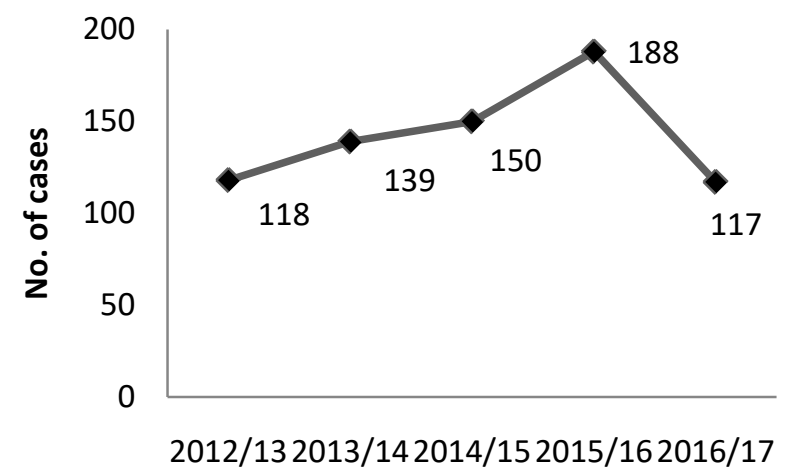

D

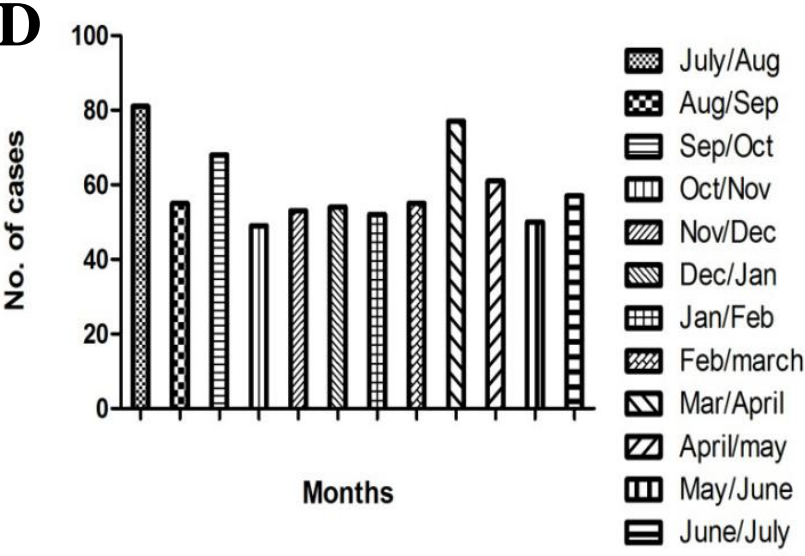

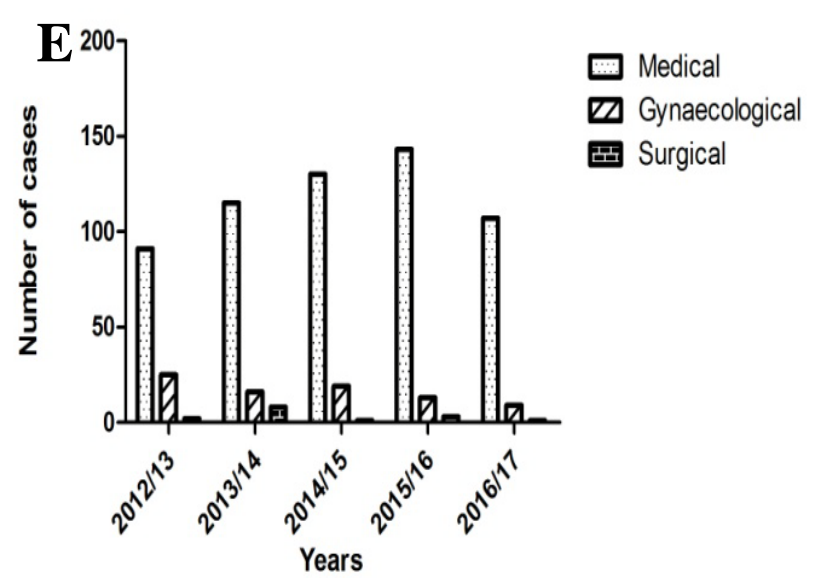

$\mathbf{F}$

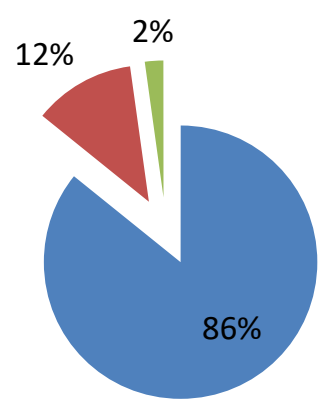

- Medical

- Gynaecological

- Surgical

Figure 1. Diagram showing different categories wise distribution of buffaloes cases presented at VTH from 2012-2017 (A-Age, B-Year, C- Season, D-Month, E- Disease versus year, F-Disease).

Among the various cases FE was found the most frequently registered problem which was (490) $72 \%$. Similarly, mastitis, anestrous, PD and others were (82) 12\%, (37) 5\%, (45) 7\% and 20 (3\%) respectively (Figure 2). 


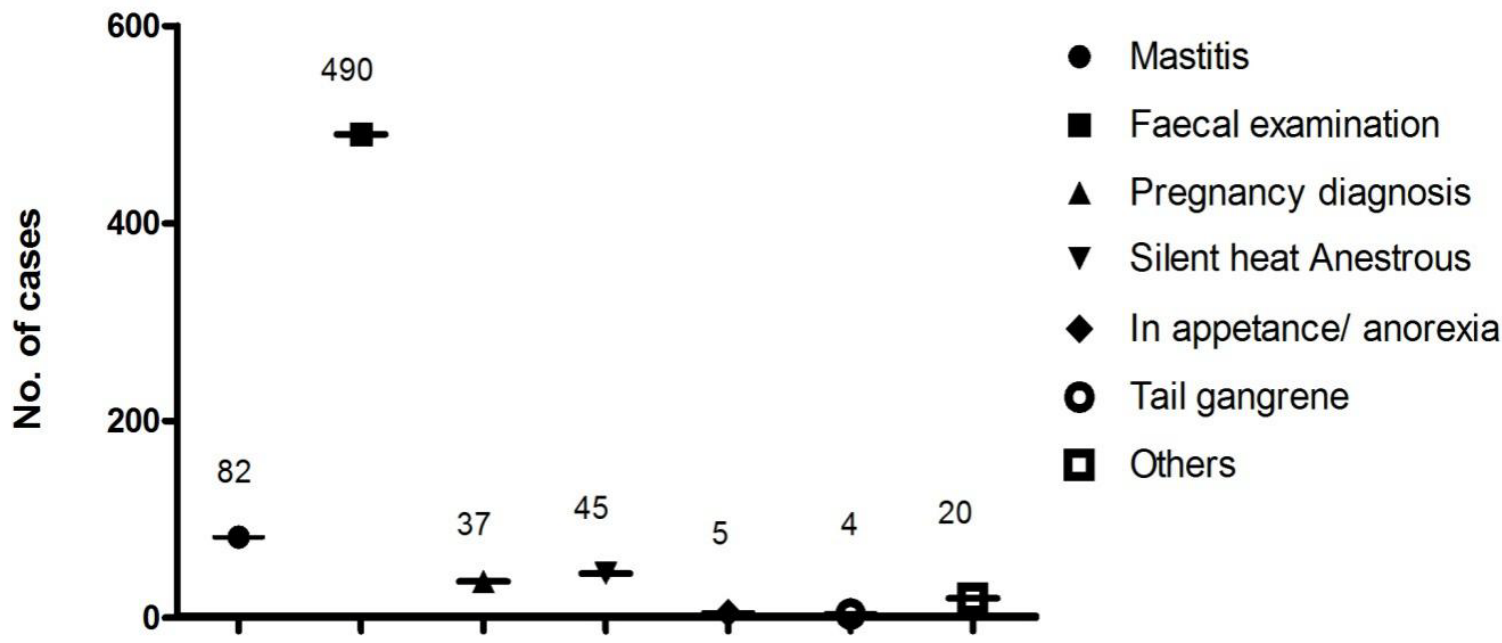

\section{Diseases and disorders}

Figure 2. Disease wise case flow pattern of buffaloes presented at VTH from 2012-2017.

Mastitis was the second most frequently registered case in the hospital. The distribution was found throughout but the highest cases were found in the month July/Aug and Sep/Oct (Figure 3B). Seasonal occurrence of mastitis was found highest during autumn followed by summer, winter and spring (Figure 3A). The highest cases of mastitis were recorded in the first parity/calving followed by third and second parity (Figure 3C). In the antibiogram, ciprofloxacin (31\%), gentamicin (33\%), tetracycline (16\%), chloramphenicol (7\%), enrofloxacin (4\%) and amikacin (9\%) were found sensitive (Figure 3D).
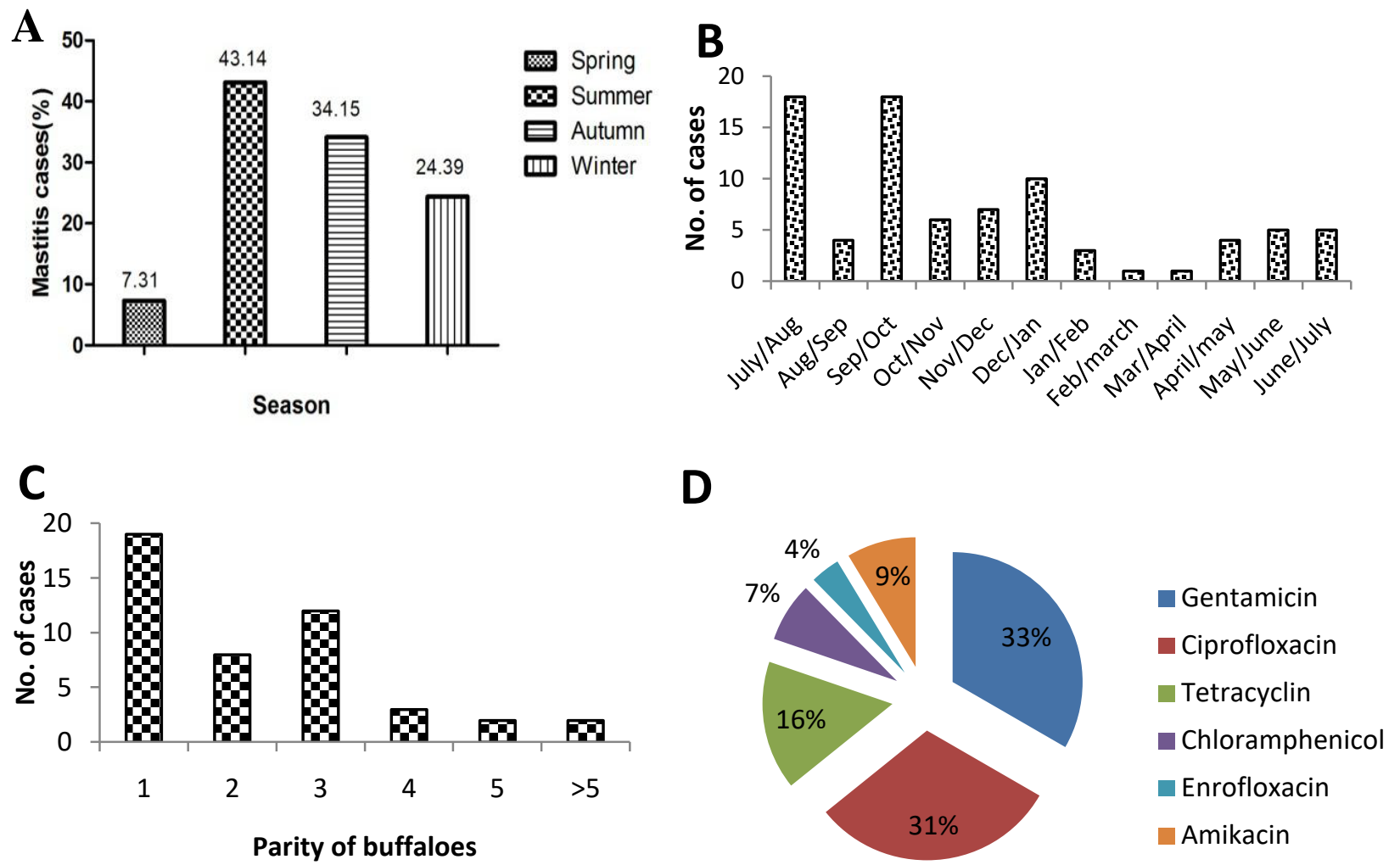

Figure 3. Diagram showing the distribution of mastitis cases brought to VTH from 2012-2017 based on (A-Season, B-Month, C-Parity, D-Antibiotic Sensitivity). 
The occurrence of clinical mastitis in during different months was recorded (Table 1). The maximum number of cases of clinical mastitis was observed in the month of July/Aug (21.95\%) and Sep/Oct (21.95\%) followed by Dec/Jan (12.19\%). Results show that $43.14 \%$ of buffaloes had clinical mastitis during summer season followed by the autumn season (34.15\%).

Table 1. Prevalence of clinical mastitis at different months and seasons recorded at VTH from the year 2012-2017

\begin{tabular}{|c|c|c|c|c|}
\hline Seasons & Months & Cases & Percent & \\
\hline \multirow[t]{3}{*}{ Spring } & Feb/march & 1 & 1.21 & \\
\hline & Mar/April & 1 & 1.22 & 7.32 \\
\hline & April/may & 4 & 4.88 & \\
\hline \multirow[t]{3}{*}{ Summer } & May/June & 5 & 6.09 & \\
\hline & June/July & 5 & 6.09 & 34.15 \\
\hline & July/Aug & 18 & 21.95 & \\
\hline \multirow[t]{3}{*}{ Autumn } & Aug/Sep & 4 & 4.88 & \\
\hline & Sep/Oct & 18 & 21.95 & 34.15 \\
\hline & Oct/Nov & 6 & 7.32 & \\
\hline \multirow[t]{3}{*}{ Winter } & Nov/Dec & 7 & 8.54 & \\
\hline & Dec/Jan & 10 & 12.19 & 24.39 \\
\hline & Jan/Feb & 3 & 3.66 & \\
\hline
\end{tabular}

Mastitis is a managemental disease caused by unhygienic condition of the shed and milking practices mainly due to gram negative bacteria like coliform (Escherichia, Klebsiella, Enterobacter) and gram positive bacteria like Staphylococcus, Streptococcus etc., and fungus. Among the cultured cases 85\% were coliform, 12\% Staphylococcus, 3\% Klebsiella and 3\% with no growth that may be due to fungal cause or the antibiotic used due to suspicion of sub-clinical mastitis (Figure 4).

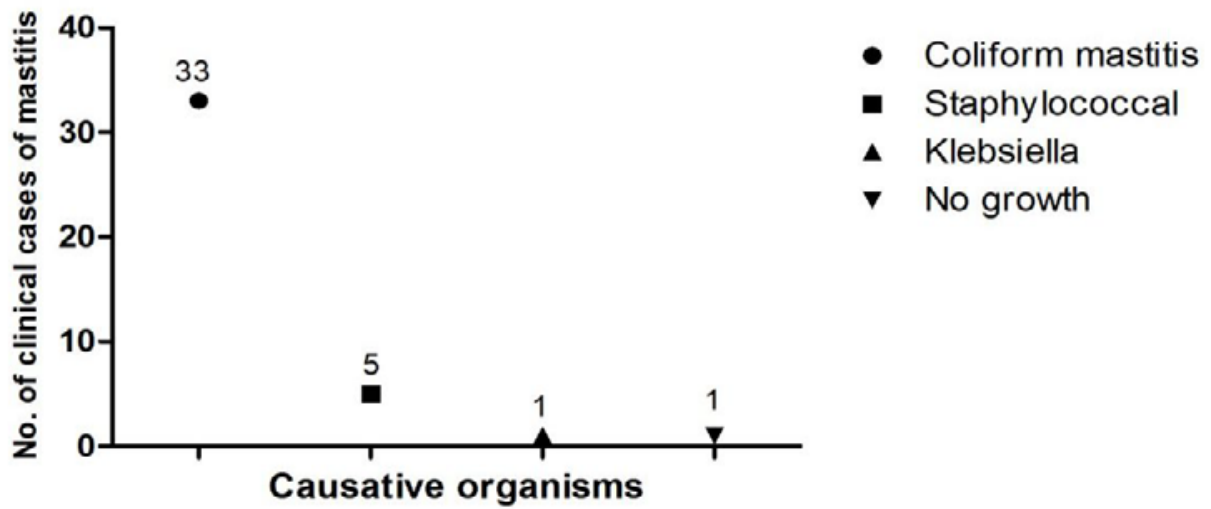

Figure 4. Cause of mastitis diagnosed at VTH from the year 2012-2017.

In present study, reproduction related cases were PD, anestrous and repeat breeding. The case flow for PD was highest during winter followed by spring, summer and autumn (Figure 5A). Month wise occurrence of PD cases as shown in the Figure 5B suggests that highest cases registered in March/April followed by equal no of cases in the month Jan/Feb and Aug/Sep. Similarly, anestrous, silent heat and repeat breeding cases were found maximum during autumn season followed by spring, winter and summer (Figures 5C \& D).
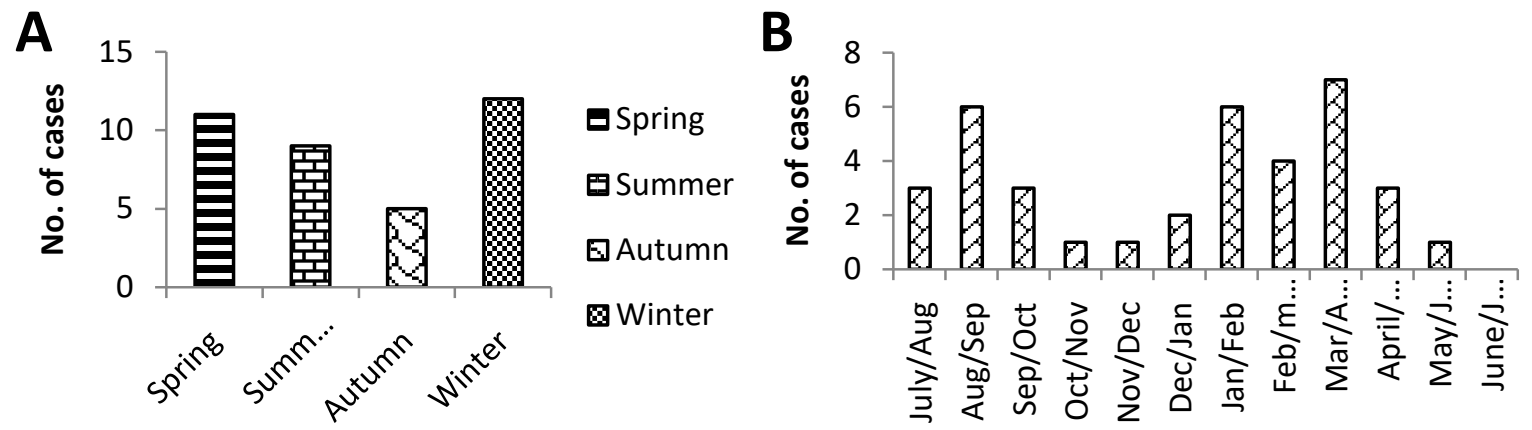

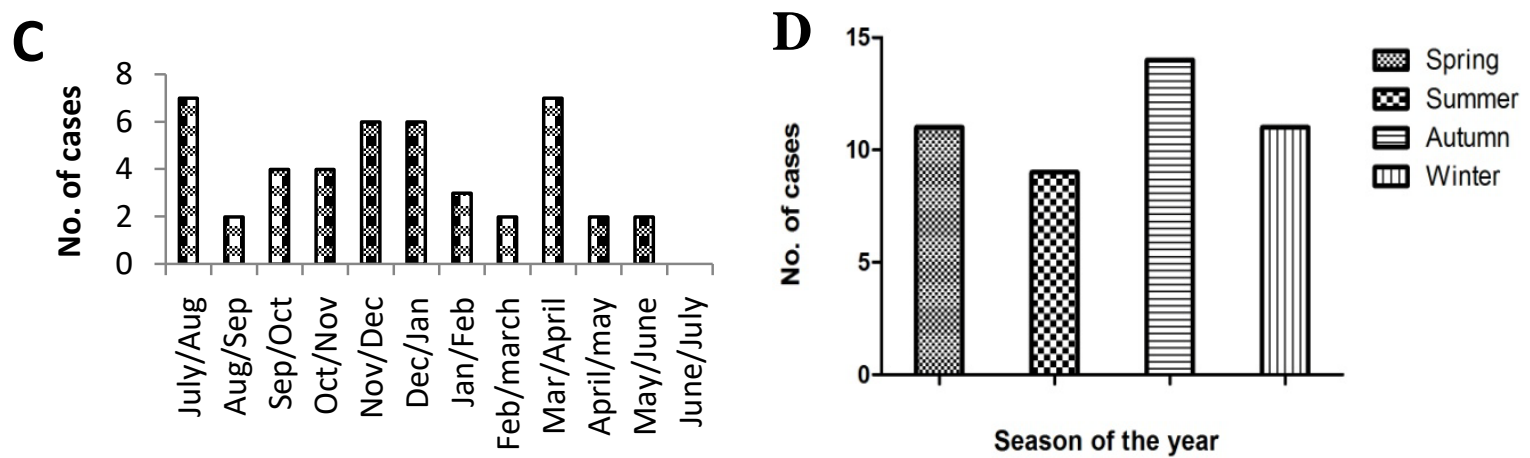

Figure 5. Gynecological buffalo cases registered at VTH from 2012-2017 and their diagrammatical presentation based on (A-season wise PD, B-Month wise, C- Month-wise anestrous, silent heat, repeat breeding, D- Season wise anestrous, silent heat, repeat breeding).

Out of the total samples (490) 72\% carried for FE, 83\% were found positive for the endoparasites (Figure 6A). Among them nematodes were 44\%, Paramphistomes 35\%, Fasciola 5\%, protozoa 10\% and Moneizia $6 \%$ (Figure 6B). Cases of parasitic infestations were found maximum during spring season followed by summer and autumn (Figure 6C).
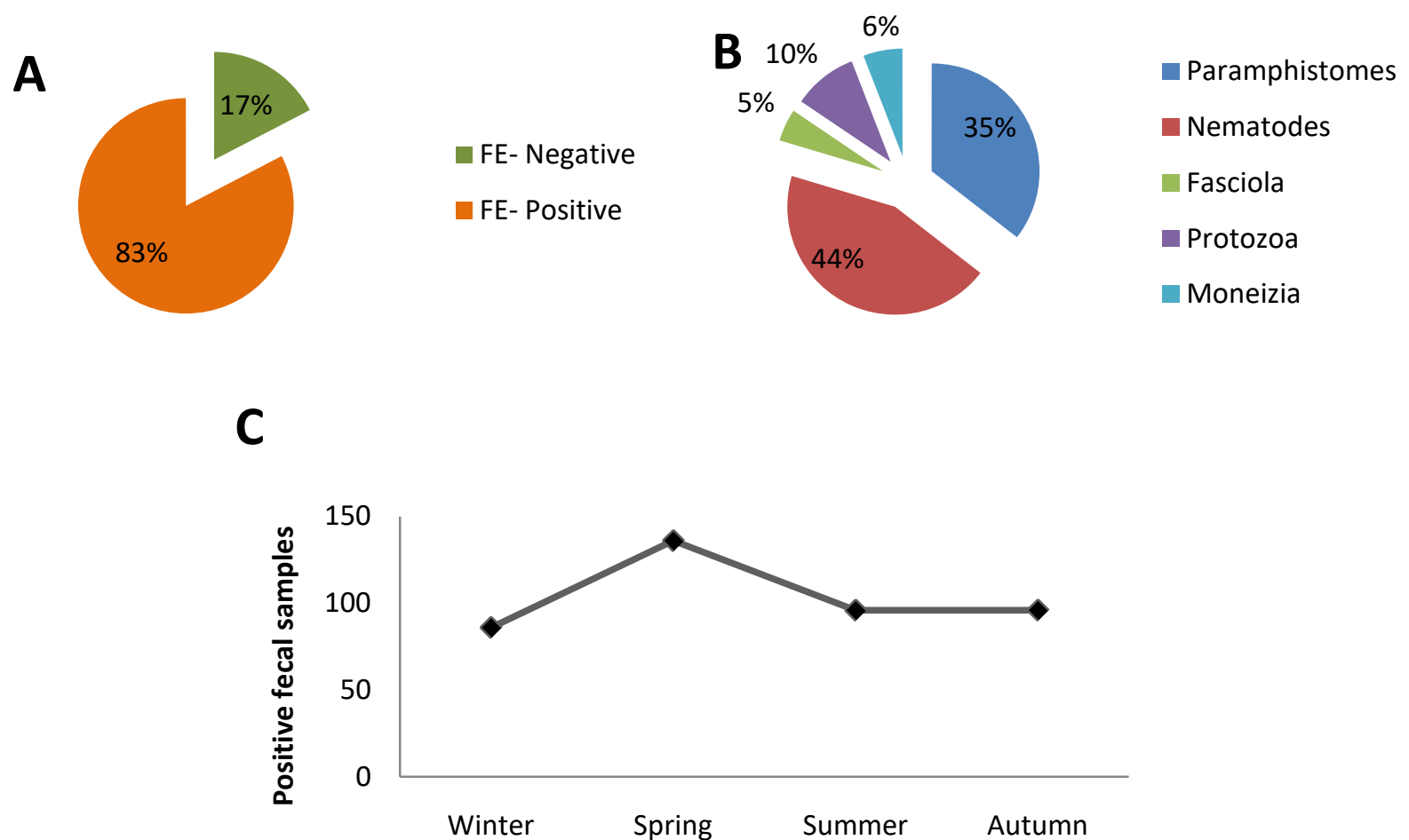

Figure 6. Graphical representation of FE of buffaloes recorded at VTH from the year 2012-2017 (A- Prevalence of endo-parasites, B- prevalence of different endo-parasites, $C$ - Seasonal variation of endo-parasites in the sample positive for FE).

\section{Discussion}

Adult patients were most frequently registered cases followed by heifers, seniors and yearlings. It is obvious that the adults produce milk and meat. So, farmers pay much concern with the health status of adult buffaloes. The heifer was the second most registered patients because it is a wealth of herd. They are in the stage of to be productive; they will be future dam and source of milk and meat. In other aspect, they are more susceptible to disease and disorders and the owner is also more worried about the health of their livestock at this stage. The farmers commonly visits the hospital for artificial insemination, PD, FE, mastitis test, milk culture and anestrus which are the major problems and conditions occurring in the reproductive and productive life of the animals. Based on sex wise case flow pattern, the male: female ratio was 1:49 which suggests that the farmers rear very less number of he-buffaloes commercially for meat production 
and natural insemination. Rearing of he-buffaloes is replaced by recent biotechnology in artificial insemination (AI). Nowadays, farmers are more conscious about the benefit of AI viz genetic improvement, increased milk production, no cost for rearing of breeding bull. Murrah and murrah-cross (99\%) were the major buffalo breed reared around hospital which is also supported by Devkota et al. [8]. They found that $99 \%$ of buffaloes were murrah-cross and found all improved breed in a household survey conducted in the Chitwan district.

The total number of buffalo cases brought to VTH from the FY 2012/13 to 2015/16 was in increasing trend. This result is support by Gautam et al. [6] who reported the increasing trend of cases from the FY 2014/15 to 2015/16. But the number of cases found to be decreased during the FY 2016/17. Increase in the number of private veterinary clinics and agro-vet centers at various places around the vicinity of VTH may be the possible reason behind decrease in the number of cases. The farmers prefer to take their sick buffaloes to nearby clinics rather than to bring to far at VTH. Also the home service and on call service provided by the vets, vet students and technicians render the owners easier to treat the sick animals. There were a fairly small number of surgical cases which might be due to the lack of 24 hours emergency facility, inpatient and ambulance service at the VTH. The large number of animal farmers prefer to call vets and technician to home for surgical cases rather than taken to hospital. As most of the surgical cases being emergency condition, they need immediate correction. It is essential to increase the number of overall cases and especially surgical cases brought to the VTH by providing the ambulance service in order to make veterinary students exposure to such cases and proper aseptic handling of surgical cases. Gautam et al. [6] suggested the concerned authorities either to start ambulatory clinical service at nominal cost or run clinical practice classes at farmer's community.

The highest numbers of cases were observed in the month July/Aug followed by March/April and Sep/Oct. Overall cases were found to be highest in summer followed by spring, autumn and winter season respectively. Weather conditions such as rainfall, flooding, humidity, and heat waves have well-documented effects on infectious diseases [12]. Among the various cases brought to VTH, FE shared the highest proportion which is in agreement with the previous studies [6, 9]. In present study, more than three-quarter of the fecal samples brought to VTH were positive for endoparasitic eggs with the highest prevalence of Paramphistomum followed by nematodes, protozoa, Moneizia and Fasciola. In the seasonal variation, the highest prevalence of endoparasitic infestation was found in the spring followed by equal prevalence in summer and autumn and least in the winter season. This means that the prevalence of endoparasitic infestation is lower in the winter season and higher in spring/rainy season. Rainy season is very suitable period for the helminthes reproduction which may be due to the high humidity in this period [13]. Therefore, it is important to administer the anthelmintic to the livestock before the commencement of rainy season as a prophylactic measure.

PD, anestrous, silent heat and repeat breeding cases were the major reproductive cases in the study area. The PD cases were found highest during the month March/April followed by Aug/Sep and Jan/Feb. Similarly, the anestrous (silent heat and repeat breeding) cases were found highest in the month March/April and July/Aug followed by Nov/Dec and Dec/Jan. The reproductive failure cases were found maximum during autumn followed by spring, winter and summer. These findings did not show a clear seasonal variation in case flow of PD. This may be due to farmers not having schedule pregnancy test, they come to vets only when they suspect that animal is not gaining weight or animal come to heat repeatedly. Schedule pregnancy test after 2-3 months of service can be incorporated for better accuracy of pregnancy rate through rectal palpation.

In the present report, the highest prevalence of organisms causing mastitis was coliform followed by Staphylococcus and Klebsiella. Dhakal [11] was carried out a study on 165 buffalos at different villages of Chitwan district and found that coliform was the most frequently isolated organisms (27\%) followed by Staphylococcus (19\%) and Streptococcus (8\%). Sharma et al. [10] also reported that the major mastitis causing organisms were Staphylococcus, Streptococcus, E.coli, Corynebacterium and Klebsiella. The highest incidence of clinical mastitis was found in summer followed by autumn, winter and spring season. Similarly, the greatest number of clinical cases of mastitis was observed in the month of July/Aug and Sep/Oct. The maximum numbers of cases were affected with clinical mastitis at $1^{\text {st }}$ calving followed by $3^{\text {rd }}$ and $2^{\text {nd }}$ parity. Dhakal et al. [7] also reported the similar findings in the milk samples from 355 Murrah cross buffaloes brought to VTH, Rampur, Chitwan. They also reported the greatest number of buffaloes being affected with clinical mastitis at $1^{\text {st }}$ calving followed by $2^{\text {nd }}$ and $3^{\text {rd }}$ calving.

\section{Conclusion and Recommendation}

Mastitis, parasitic infestation and anestrous/silent heat were found the major clinical cases of buffaloes. Seasonal pattern of various diseases presented in this study could be insightful for outlining the appropriate disease control and management strategies around the university vicinity. The total cases flow tendency is not pleasing especially the surgical cases. Inpatient facility, ambulatory and 24 hours emergency services might be the possibilities in order to increase the flow of such cases. The concerned authority should pay special attention to update their services and technologies for the disease diagnosis and treatment that will benefit the farmers as well as the students to develop their 
clinical skills.

\section{Conflict of Interest}

The authors declare that there is no conflict of interest.

\section{References}

[1] Sharma, B., \& Banskota, K. (2012). Smallholder Dairy Farming in Nepal: Characteristics, Constraints, and Development Opportunities. Retrieved from http://lib.icimod.org/record/21368/files/c_attachment_79_555.pdf?version=1.

[2] FAO. (2015). Water buffaloes. Retrieved August 18, 2017, from http://www.fao.org/agriculture/dairy-gateway/milk-production/dairy-animals/water-buffaloes/en/\#.WZaqufgjHIV.

[3] MoAD. (2016). Statistical information on nepalese agriculture. Monitoring, Evaluation and Statistics Division Agri Statistics Section. Ministry of Agricultural Development, Government of Nepal. Retrieved from http://moad.gov.np/public/uploads/1142453195-Statistic Agriculture Book_2016.pdf.

[4] Paudel, L. N., Meulen, U. ter, Wollny, C., Kandel, U. P., \& Gauly, M. (2008). Indigenous Buffalo Farming and its Improvement: A Potential Drive for Rural Development in Nepal Main indigenous buffaloes in Nepal Main constraints for improved buffalo farming in Nepal. Retrieved August 18, 2017, from http://www.tropentag.de/2008/abstracts/posters/251.pdf.

[5] Devkota, B., \& Bohora, T. P. (2009). Effects of Season on Pregnancy Rates in Water Buffaloes of Southern Nepal Evaluated by Using Different Estrus Synchronization Protocols During Active Season and Low Breeding Season. Pakistan Journal of Zoology, 9, 763-770.

[6] Gautam, G., Devkota, B., \& Thapaliya, S. (2017). Recent case flow pattern in veterinary teaching hospital of agriculture and forestry university, Chitwan, Nepal. Journal of Agriculture and Forestry University, 1, 119-128.

[7] Dhakal, I. P., Dhakal, P., Koshihara, T., \& Nagahata, H. (2007). Epidemiological and bacteriological survey of buffalo mastitis in Nepal. The Journal of Veterinary Medical Science/the Japanese Society of Veterinary Science, 69, 1241-1245. https://doi.org/10.1292/jvms.69.1241.

[8] Devkota, D., Devkota, N. R., \& Joshi, N. P. (2015). Gender role and buffalo rearing decisions in Nepal. _Nepalese Journal of Agricultural Sciences, 1(13).

[9] Gautam, R., Bhandari, D. P. \& Dhakal, I. P. (1999). Retrospective study of the common livestock and poultry diseases in Chitwan, Nepal. The Blue Cross, 3, 3-5.

[10] Sharma, N., Rho, G. J., Hong, Y. H., Kang, T. Y., Lee, H. K., Hur, T. Y., \& Jeong, D. K. (2012). Bovine Mastitis: An Asian Perspective. Asian Journal of Animal and Veterinary Advances, 7(6), 454-476. https://doi.org/10.3923/ajava.2012.454.476.

[11] Dhakal, I. P. (1997). Drug selection and use on clinical mastitis in buffaloes at Chitwan Valley of Nepal. Bubalus bubalis. 11: 56-70.

[12] Polgreen, P. M. \& Polreen E. L. (2018). Infectious diseases, weather, and climate. Clinical Infectious Diseases, 66(6), 815-817. https://doi.org/10.1093/cid/cix1105.

[13] Silva, C. D, Avila, R. W \& Morais, D. H. (2018). Helminth Community Dynamics in a Population of Pseudopaludicola Pocoto (Leptodactylidae: Leiuperinae) from Northeast-Brazilian. Helminthologia, 55(4): 292-305. doi: 10.2478/helm-2018-0032. 